\title{
RESEARCH
}

IN BRIEF

- An investigation of morbidity experienced by patients following chin graft procedures for augmentation of maxilla or mandible.

- When treatment options are being discussed with a patient, it is important for the GDP and specialist to fully inform the patient of the possible morbidities that can be experienced at the donor site.

- This paper will inform GDPs and specialists who may be considering referral of patients for such treatment.

\section{An investigation of post-operative morbidity following chin graft surgery}

\author{
A. Joshi ${ }^{1}$
}

\begin{abstract}
Aim The aim of this prospective study was to evaluate the morbidity at the donor site following harvest of chin bone for intra-oral augmentation.

Method The morbidity experienced by 27 consecutive patients who had undergone chin bone harvesting to augment intra-oral sites prior to implant placement at the Department of Oral and Maxillofacial Surgery, University Dental Hospital of Manchester was evaluated at one week, one, three and 12 months post-operatively.

Results Nine (33\%) patients suffered post-operative morbidity. One patient experienced paraesthesia of the chin and lower lip and a further patient, paraesthesia of the gingivae immediately post-operatively. Both patients had full recovery when reviewed at three months. Two patients experienced pain at the graft site for up to three months postoperatively. Five (18.5\%) patients experienced woodiness/ numbness of the lower anterior teeth at the first post-operative visit and at 12 months, two patients continued to have no sensitivity in the lower anterior incisor teeth. None of the patients reported altered contour or change in profile of the chin area. Twenty-three (85.2\%) patients had successful grafts with placement of implants thereafter.

Conclusion It is important for GDPs and specialists to make patients aware of the possible morbidities following harvest of bone from the chin.
\end{abstract}

Increasingly, patients demand osseointegrated implants following tooth loss. However, the residual alveolar ridge may have atrophied or have defects which may complicate placement of an implant. Furthermore, some patients present with oligodontia or hypodontia and adequate bone does not exist in the bucco-lingual dimension for optimal functional and aesthetic prosthetic reconstruction. Autogenous bone grafts are available from extra and intra-oral donor sites. ${ }^{1,2}$ Extra-oral donor sites include iliac crest, calvarium, tibia, ribs and intra-oral sites include maxilla, mandible and zygoma. The choice of donor site is dependent upon the quantity of bone required, access to the donor site, difficulty

${ }^{*}$ Lecturer, University Dental Hospital of Manchester, Higher Cambridge Street, Manchester $\mathrm{M} 156 \mathrm{FH}$

*Correspondence to: Dr A Joshi

Email:Ameeta.joshi@man.ac.uk

Refereed paper

Received 15.01.03: Accepted 02.05.03

doi:10.1038/sj.bdj.4810987

๑ British Dental Journal 2004; 196: 215-218 with and time required for harvesting procedures and the cost. ${ }^{1,3,4}$ The mandibular symphysis is a favourable donor site because it is generally assumed that it has an excellent risk-benefit ratio. ${ }^{5}$ The advantages of chin bone harvesting are outlined in Table 1.

Table 1 Advantages of chin bone harvesting

- Proximity of recipient site to harvest site

- Ease of access to tissue

- Benefit of using intra-membranous bone versus endochondral bone

- Embryonic origin means early vascularisation and less resorption

- Minimal patient concern for altered facial contour

- No cutaneous scar

- Short healing period

- No hospitalisation or alteration in ambulation

- Minimal morbidity

However, disadvantages of harvesting bone from the chin area include: sensory disturbance, altered sensation and sensitivity of lower anterior teeth and intra-oral scarring.

The aim of this prospective study was to evaluate the morbidity at the donor site following harvest of chin bone for intra-oral augmentation.

\section{METHOD}

Approval of the Trust Ethical Committee was obtained together with written informed consent from patients. Twenty-seven consecutive patients who had undergone chin bone harvesting to augment intra-oral sites prior to implant placement between March 2000 to March 2002 at the Department of Oral and Maxillofacial Surgery, University Dental Hospital of Manchester were requested to participate in the study. Post-operative morbidity was examined by completion of the assessment form as outlined in Table 2 . The patients had been operated on by three surgeons.

\section{SURGICAL PROCEDURE}

Prior to commencing the surgical procedure, patients use a mouth rinse of chlorohexidine $0.2 \%$ to reduce intra-oral bacterial load. Ten mls of Bupivicaine (0.25\%) with 1:200,000 adrenaline is infiltrated in the lower intercanine area buccally and lingually. With the lip drawn anteriorly, the soft tissues are placed under tension and the incision is made in two layers, firstly through mucosa and then through the muscle and periosteal 
Table 2 Post-operative morbidity assessment form

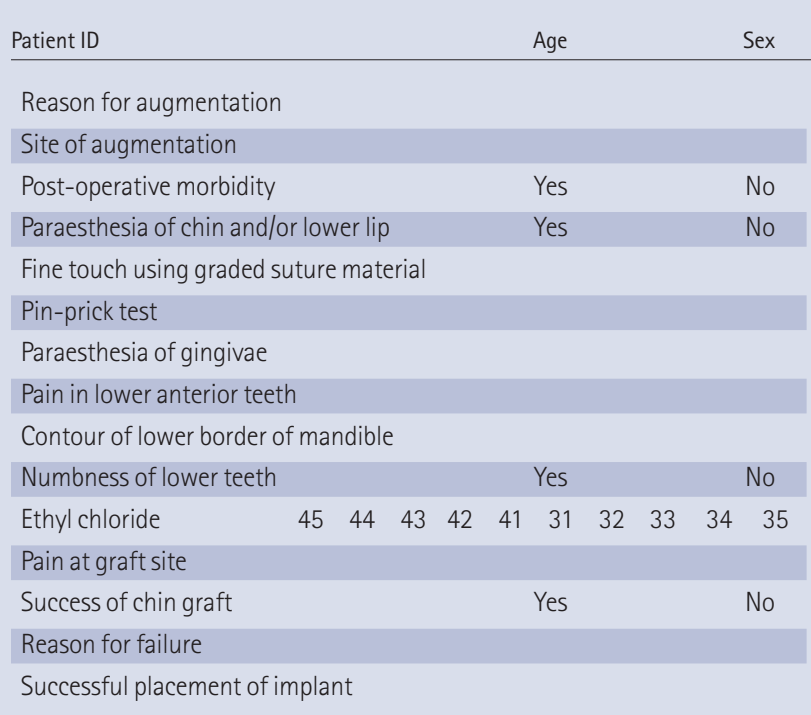

layers A full thickness mucosal flap is raised following a vestibular incision in the intercanine region $5 \mathrm{~mm}$ below the muco-gingival junction. Periosteal elevation is performed to the inferior border of the mandible to expose the symphysis. Careful and gentle blunt dissection bilaterally exposes the mental foramina. The dimensions of the graft to be harvested will already have been established from the recipient site by using a template cut from residual card from a suture packet. This template is overlaid onto the exposed mandible ensuring $5 \mathrm{~mm}$ safety margin below the apices of the lower anterior teeth and allowing a $5 \mathrm{~mm}$ thickness of the lower border of the mandible. The osseous cuts are either made with a Khoury saw (Khoury Kit) or a very fine fissure bur under copious irrigation with saline. A cortico-cancellous bone block is harvested with the aid of a $3 \mathrm{~mm}$ osteotome (Khoury Kit), which is tapped into the outline with a mallet. Patients should be asked to clench their teeth in centric occlusion and the surgical assistant must provide support to the chin during the tapping phase. Further cancellous bone is harvested with a Volkman's spoon. The volume of bone harvested is deemed to be sufficient to augment local bone defects at the recipient site. The harvested bone is stored in a gauze soaked in sterile saline. A further saline soaked gauze is then placed at the donor site. Before the graft is secured at the recipient site, it is prepared by creating tiny perforations in the cortical bone with a small round bur to stimulate active bleeding. The graft and the recipient site should be modified to fit as closely as possible onto the recipient site. The graft is secured to the recipient site with a $1.5 \mathrm{~mm}$ titanium screw or additional screws may be required for a larger graft. After the graft is secured firmly, any defects are filled in with harvested cancellous bone. The flap is undermined and is sutured without tension with polyglactic sutures.

After the recipient site is completed, closure of the donor site is undertaken. The saline soaked gauze is removed and the area is irrigated with saline. To ensure that the missing bone is able to regenerate, the defect is filled with Bio-Oss (Geistlich). This is deproteinised bovine bone, which has been extensively studied in relation to its ability to provide a scaffold for bone formation. BioOss was mixed with the patient's blood and packed into the defect. The site is then covered with a resorbable collagen membrane (BioGide, Geistlich). Suturing of the donor site is done in two layers, the periosteum and muscle layer are sutured first followed by the overlying mucosa. A pressure dressing is applied to the patient's chin and antibiotic therapy and analgesics are prescribed.

\section{EVALUATION}

All the patients were examined pre-operatively and one week, one, three and 12 months post-operatively. Both the donor and recipient sites were examined. This paper will concentrate on the examination at the donor site, which included contour of the chin and sensibility of the chin and lower lip. Simple tests such as those used to assess lingual nerve damage were used to confirm sensory loss and to quantify the degree of functional disturbance postoperatively. These included fine touch using graded suture materi$\mathrm{al}^{6}$ and assessment of pain using the pin-prick sensation. ${ }^{7}$ Patients were also asked whether they had experienced altered sensation of their gingiva, mucosa and the skin area innovated by the mental nerve. Sensory function was defined as follows: when a patient reported diminished sensation without the presence of pain then this was defined as paraesthesia. Anaesthesia was related to complete absence of sensation and dysaesthesia was characterised by an altered sensation with discomfort and pain. Lower anterior teeth were tested pre and post-operatively with ethyl chloride sprayed onto a small cotton wool pledget. Any loss of sensitivity of lower anterior teeth was recorded.

\section{RESULTS}

Of the 27 patients who underwent harvesting of chin grafts, 13 were male and 14 were female. The age range was 15-64 (mean 26.9). The reasons for augmentation were 11 (2m, 9f) patients had congenitally missing teeth, 13 patients $(9 \mathrm{~m}, 4 \mathrm{f})$ had lost upper anterior teeth through trauma and of the other 3 patients, one female had lost a previous implant, another had a failed crown and the third (male) patient had lost central incisors through resorption of the roots by unerupted canines. Figure 1 shows that the most common site of augmentation was the upper central/ lateral incisor area.

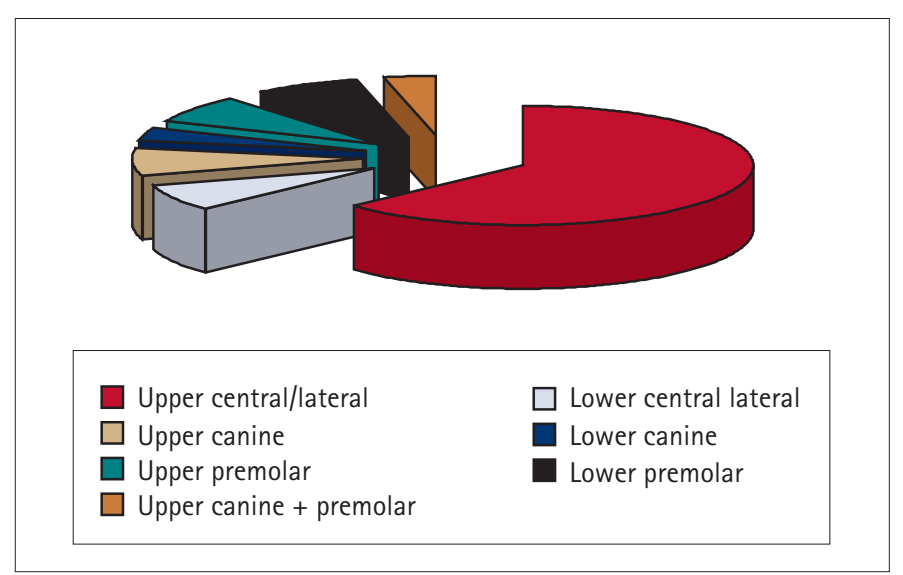

Fig. 1 Site of augmentation

Nine (33\%) patients suffered post-operative morbidity. One patient experienced paraesthesia of the chin and lower lip and a further patient, paraesthesia of the gingivae immediately postoperatively. Both patients had full recovery when reviewed at three months. Five (18.5\%) patients experienced woodiness/ numbness of the lower anterior teeth at the first post-operative visit. Pulp sensitivity of the lower teeth was examined with ethyl chloride and is shown in Table 3.

Commonly, the lower anterior incisor teeth were affected and in two patients at 12 months post-operatively, the lower anterior teeth did not react sensitively. None of the patients reported altered contour or change in profile of the chin area. Two patients experienced pain at the graft site for up to three months postoperatively. Twenty-three (85.2\%) patients out of 27 had successful grafts with placement of implants thereafter. Of the other four, two patients who were students had left the area to pursue educa- 
RESEARCH

Table 3 Reduced sensation of lower teeth

\begin{tabular}{|c|c|c|c|c|c|c|c|c|c|c|}
\hline \multirow[b]{2}{*}{ Patient No. } & \multicolumn{10}{|c|}{ Tooth number } \\
\hline & 45 & 44 & 43 & 42 & 41 & 31 & 32 & 33 & 34 & 35 \\
\hline 1 & + & + & + & - & - & - & + & + & + & + \\
\hline 2 & + & + & + & - & - & - & - & + & + & + \\
\hline 3 & + & + & + & + & - & - & - & - & + & + \\
\hline 4 & + & + & + & + & - & - & - & + & + & + \\
\hline 5 & + & + & + & + & - & - & + & + & + & + \\
\hline
\end{tabular}

tional studies abroad. They returned 6 and 14 months after grafting and unfortunately resorption of the chin graft had occurred. A further graft was harvested for these two cases. One patient was lost in the system and had not been given appropriate optimal appointments after grafting for placement of the implant. The other patient had graft resorption at 12 weeks, but there was no obvious reason for this.

\section{DISCUSSION}

The mandibular symphysis is the most commonly used intra-oral donor site. The harvested bone is highly osteogenic and provides a scaffold for bone regeneration. The augmented alveolar bone is then adequate enough to allow optimal implant placement. The advantage of the mandibular symphysis as a donor site is that it is readily accessible and carries little morbidity. ${ }^{3}$ The morbidity can still be a problem for patients and it is important to highlight such morbidities to patients before considering intra-oral augmentation.

Although this prospective study confirms that morbidity resulting from such procedures is low, recovery can be slow and a problem to patients. Apart from one study by Nkenke et al. ${ }^{8}$ previous studies have been of a retrospective nature and objective assess- ment of nerve function has not been done (Table 4). Nine patients suffered post-operative morbidity. One week post-operatively, two of these patients (7.4\%) had experienced paraesthesia of the chin and lower lip and gingiva respectively, however full recovery had occurred at three months. The results in this study compare favourably with those discussed in Table 4 . The most likely reason for the paraesthesia is due to neuropraxia of the incisive nerve or the terminal branches of the mental nerve. The incidence of temporary mental nerve paraesthesia is thought to be approximately $10 \%$ and post-operative neuropraxia is not uncommon. ${ }^{1}$ When a chin graft is harvested, the mental nerve is often stretched and it is important not to underestimate the distance of the inferior alveolar nerve because of the S-shaped course of the nerve before leaving the mandible. ${ }^{9}$ It is therefore important to assess nerve function pre-operatively and patients should be warned of the possibility of altered sensation of the gingiva, lower lip and chin post-operatively.

Altered sensation of the lower teeth is also a common temporary post-operative symptom. ${ }^{10}$ Five $(18.5 \%)$ of patients experienced woodiness/numbness of the lower anterior teeth at the first post-operative visit. Commonly lower anterior incisor teeth were affected. At 12 months, two patients continued to have no sensi-

\begin{tabular}{|c|c|c|c|}
\hline Authors & Number of patients & Immediate morbidity & Morbidity after 3 months post-operatively \\
\hline Sindet-Pedersen and Enemark $1988^{11}$ & 28 & None & None \\
\hline Sindet-Pedersen and Enemark $1990^{12}$ & 20 & None & None \\
\hline Jensen and Sindet-Pedersen $1991^{13}$ & 26 & $\begin{array}{l}\text { Hypoaesthesia } \\
5 \text { patients }\end{array}$ & None \\
\hline Hoppenreijs etal. $1992^{14}$ & 26 & None & $\begin{array}{l}\text { Non-sensitive front teeth } \\
4 \text { patients }\end{array}$ \\
\hline Misch et al. $1992^{3}$ & 11 & None & None \\
\hline Jensen et al. $1994^{15}$ & 39 & $\begin{array}{l}\text { Hypoaesthesia } \\
8 \text { patients }\end{array}$ & $\begin{array}{l}\text { Stained canine } \\
1 \text { patient }\end{array}$ \\
\hline \multirow[t]{2}{*}{ Misch $1997^{1}$} & 31 & $\begin{array}{l}\text { Dehiscence of incision } \\
3 \text { patients }\end{array}$ & $\begin{array}{l}\text { dull sensation in incisors } \\
9 \text { patients }\end{array}$ \\
\hline & & $\begin{array}{l}\text { Paraesthesia } \\
3 \text { patients }\end{array}$ & $\begin{array}{l}\text { Paraesthesia persisted for } \\
\text { longer than 6th months }\end{array}$ \\
\hline Widmark et al. $1997^{16}$ & 9 & $\begin{array}{l}\text { Hypoaesthesia } \\
2 \text { patients }\end{array}$ & None \\
\hline Von Arx and Kurt $1988^{17}$ & 15 & $\begin{array}{l}\text { Non-sensitive teeth } \\
13 \text { patients }\end{array}$ & $\begin{array}{l}\text { Non-sensitive teeth } \\
3 \text { patients and staining } 32\end{array}$ \\
\hline Nkenke et al. $2001^{8}$ & 20 & $\begin{array}{l}\text { Sensory impairment } \\
8 \text { patients } \\
\text { non-sensitive teeth } 21.6 \%\end{array}$ & $\begin{array}{l}\text { Hypoaesthesia after } \\
12 \text { months } 2 \text { patients, } \\
\text { Non-sensitive teeth } 11.4 \% \text { after } 12 \text { months }\end{array}$ \\
\hline Raghoeber et al. $2001^{18}$ & 21 & $\begin{array}{l}\text { Dehiscence of incision } \\
1 \text { patient } \\
\text { Prolonged post-operative } \\
\text { pain } 9 \text { patients } \\
\text { Altered sensation in incisors } \\
4 \text { patients } \\
\text { Paraesthesia of the chin } \\
9 \text { patients }\end{array}$ & $\begin{array}{l}\text { Paraesthesia in chin } \\
\text { region } 7 \text { patients } \\
4 \text { patients experienced } \\
\text { meteorotropism } \\
\text { (weather-related discomfort) }\end{array}$ \\
\hline
\end{tabular}


tivity in their lower anterior incisor teeth. This is in contrast with Nkenke et al. where canines were affected preferentially. ${ }^{8}$ Normally, during graft harvest, there is at least a $5 \mathrm{~mm}$ safety margin from the apices of lower anterior teeth. Perhaps the safety margin should be increased to avoid loss of sensitivity of lower anterior teeth. Animal experiments performed by Neukam et al. ${ }^{19}$ showed that the margin of safety should be at least $8 \mathrm{~mm}$ to preserve blood supply of the front teeth.

None of the patients complained of altered chin morphology and indeed recently grafts harvested from the mandibular lower border were reported to show no discernible change of significance in chin morphology. ${ }^{20}$ Twenty-three (85.2\%) patients out of 27 had successful grafts with placement of implants thereafter. Alveolar defects should be augmented at least three months before implant placement but delays greater than six months may result in resorption of the graft. ${ }^{21}$ Three patients in this study lost their bone graft at the recipient site as they returned for implant placement after three months.

Despite the above morbidities, harvesting of bone from the mandibular symphysis is successful and providing patients are fully informed of the possible risks of altered sensation of the gingiva, lower lip and chin area along with loss of sensitivity of lower anterior teeth, autogenous bone remains the best option.

1. Misch C M. Comparison of intra-oral donor sites for onlay grafting prior to implant placement. Int J Oral Maxillofac Implants 1997; 12: 767-776.

2. Tolman D E. Reconstructive procedures with endosseous implants in grafted bone: a review of the literature Int J OralMaxillofac/mplants 1995 : 10: 275-294.

3. Misch C M, Misch C E, Resnik R R, Ismail Y H. Reconstruction of maxillary alveolar defects with mandibular symphysis grafts for dental implants: a preliminary procedural report. Int J Oral Maxillofac Implants 1992; 7: 360-366.

4. Raghoebar G M, Batenburg R H K, Vissink A, Reintsema H. Augmentation of localised defects of the anterior maxillary ridge with autogenous bone before insertion of implants. J Oral Maxillofac Surg 1996; 54: 1180-1185.

5. Triplett R G, Sihow $S$ R. Osseus regeneration with bone harvested from the anterio mandible. In: Nevirs M, Mellonig J T, eds. Implant therapy. Clinical approaches and evidence of success. Chicago: Quintessence Publishing Company. 1998 pp 209217.

6. Blackburn C W. A method of assessment in cases of lingual nerve injury. Br J Oral Maxillofac Surg 1990; 28: 238-245.

7. Mason D A. Lingual nerve damage following lower third molar surgery. Int J Oral Maxillofac Surg 1988: 17: 290-294.

8. Nkenke E, Schultze-Mosgau S, Radespiel-Troger M, Kloss F, Neukam FW. Morbidity of harvesting of chin grafts: a prospective study. Clin Oral Impl Res 2001; 12: 495-502.

9. Bavitz J B, Harn S D, Hansen C A, Lang M. An anatomical study of mental neurovascular bundle - implant relationships. Int J Oral Maxillofac /mp/ 1993; 8: 563-567.

10. Misch C M, Misch C E. The repair of localised severe ridge defects for implant placement using mandibular bone grafts. Implant Dent 1995; 4: 261-267.

11. Sindet-Pedersen $\mathrm{S}$, Enemark H. Mandibular bone grafts for reconstruction of alveolar clefts. J Oral Maxillofac Surg 1988; 46: 533-537.

12. Sindet-Pedersen $\mathrm{S}$, Enemark H. Reconstruction of alveolar clefts with mandibular or iliac crest grafts: a comparative study. J Oral Maxillofac Surg 1990; 48: 554-558.

13. Jensen J, Sindet-Pedersen S. Autogenous mandibular bone grafts and osseointegrated implants for reconstruction of the severely atrophied maxilla: a preliminary report. J Oral Maxillofac Surg 1991; 49: 1277-1287.

14. Hoppenreijs T J, Nijdam ES, Freihofer H P. The chin as a donor site is early secondary osteoplasty: a retrospective clinical and radiological evaluation. J Craniomaxillofac Surg 1992; 20: 119-124.

15. Jensen J, Reiche-Fischel 0 , Sindet-Pedersen $S$. Nerve transposition and implan placement in the atrophic posterior mandibular alveolar ridge. J Oral Maxillofac Surg 1994; 52: 662-668.

16. Widmark $G$, Andersson $B$, Ivanoff C J. Mandibular bone graft in the anterior maxilla for single-tooth implants. Presentation of surgical method. Int J Oral Maxillofac Surg 1997; 26: 106-109.

17. Von Arx T, Kurt B. Endoral donor bone removal for autografts. A comparative clinical study of donor sites in the chin area and the retromolar region. Schweizer Monatsschrift Zahnmedizin 1998; 108: 446-459.

18. Raghoeber G M, Louwerse C, Kalk W, Vissink A. Morbidity of chin bone harvesting. Clin Oral Impl Res 2001: 12: 503-507.

19. Neukam FW, Hausamen J E, Kaufmann K. Animal experimental trials on the blood supply of the alveolar ridge and the teeth after alveolar osteotomy in relation to the distance of the perpendicular osteotomy line to the root apices. Deutsche Zeitschrift fur Mund-Kiefer Gesichts-Chirurgie 1981; 5: 369-372.

20. Cotter C J, Maher A, Gallagher C, Sleeman D. Mandibular lower border: donor site of choice for alveolar grafting. Br J Oral Maxillofac Surg 2002; 40: 429-432.

21. Palmer P. Palmer R. Implant surgery to overcome anatomical difficulties. Br Dent J 1999; 187: 532-540. 